\title{
Performance of a rain retrieval algorithm using TRMM data in the Eastern Mediterranean
}

\author{
D. Katsanos ${ }^{1,2}$, N. Viltard ${ }^{3}$, K. Lagouvardos ${ }^{1}$, and V. Kotroni ${ }^{1}$ \\ ${ }^{1}$ National Observatory of Athens - IERSD, Greece \\ ${ }^{2}$ University of Patras - Department of Physics, Greece \\ ${ }^{3}$ CETP/IPSL, Paris, France
}

Received: 22 November 2005 - Revised: 9 April 2006 - Accepted: 11 April 2006 - Published: 2 May 2006

\begin{abstract}
This study aims to make a regional characterization of the performance of the rain retrieval algorithm BRAIN. This algorithm estimates the rain rate from brightness temperatures measured by the TRMM Microwave Imager (TMI) onboard the TRMM satellite. In this stage of the study, a comparison between the rain estimated from Precipitation Radar (PR) onboard TRMM (2A25 version 5) and the rain retrieved by the BRAIN algorithm is presented, for about 30 satellite overpasses over the Central and Eastern Mediterranean during the period October 2003-March 2004, in order to assess the behavior of the algorithm in the Eastern Mediterranean region. BRAIN was built and tested using PR rain estimates distributed randomly over the whole TRMM sampling region. Characterization of the differences between $\mathrm{PR}$ and BRAIN over a specific region is thus interesting because it might show some local trend for one or the other of the instrument.

The checking of BRAIN results against the PR rainestimate appears to be consistent with former results i.e. a somewhat marked discrepancy for the highest rain rates. This difference arises from a known problem that affect rain retrieval based on passive microwave radiometers measurements, but some of the higher radar rain rates could also be questioned.

As an independent test, a good correlation between the rain retrieved by BRAIN and lighting data (obtained by the UK Met. Office long range detection system) is also emphasized in the paper.
\end{abstract}

\section{Introduction}

Most of the techniques (Kummerow et al., 1996; and Olson et al., 1996 for GProf; Kummerow et al., 2001 for 2A12; Bauer 2001 and Bauer et al., 2001 for PATER; Panegrossi et al., 1998 for BAMPR) used for rain retrieval from space-

Correspondence to: D. Katsanos

(katsanos@meteo.noa.gr) borne radiometer measurements rely on a database made of a large number of atmospheric profiles (and their associated brightness temperatures), that are physically consistent with the laws of atmospheric physics. Building the database itself is one of the difficulties, since the occurrences, provided most of the time through cloud model simulations, are usually limited. Furthermore, a forward radiative transfer model is necessary to associate with these cloud model profiles their brightness temperatures. This approach although it has shown satisfactory results is also strongly dependent on the database representativeness as stated by the Bayes theorem.

Very similar in its principle to the GProf algorithms (Kummerow et al., 2000), BRAIN algorithm uses a different kind of database made from co-located data between the TRMM Precipitation Radar (PR) and the TRMM Microwave Imager (TMI). This actually provides a virtually infinite database that also is fully compatible with the measurements made by TRMM satellite. In this case, the main source of error becomes the error associated with the power laws used to convert the radar reflectivity into rain rate (Viltard et al., 2000, 2006). BRAIN retrieval algorithm itself either looks for the most probable profile inside the database from the measured brightness temperature vector, or it works as an interpolation function from the space of measured brightness temperatures to the space of possible surface rain rates. The theoretical framework being the Bayes-Monte-Carlo type of technique (described also in Kummerow et al., 1996 or L'Ecuyer and Stephens, 2002). The algorithm is presented in detail in Viltard et al. (2006). The nominal resolution of BRAIN is close to TMI $37 \mathrm{GHz}$ channel i.e. about $12.5 \mathrm{~km}$. BRAIN relies only on the quality of its database and only the brightness temperatures converted into 4 emissivity indexes and 2 scattering indexes (Petty, 1994) are used for the retrieval. BRAIN was built to exhibit a very low total bias $\left(\sim-4.3 \times 10^{-2} \mathrm{~mm} / \mathrm{hr}\right)$ when compared to the PR. The rain estimates from BRAIN has a relative error that decreases as the rain rate increases from more than $+50 \%$ error below $1 \mathrm{~mm} / \mathrm{hr}$ down to $-30 \%$ for $10 \mathrm{~mm} / \mathrm{hr}$. It then improves slightly for higher rain rates stabilizing around $-26 \%$. The 


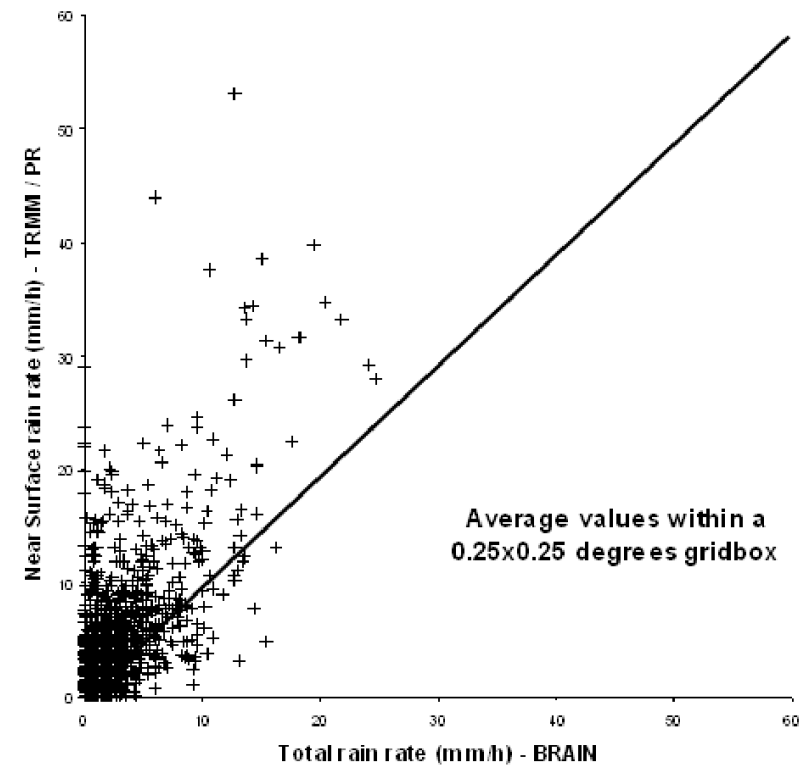

Fig. 1. Scatter plot of BRAIN rain rates and the corresponding values from PR. Values are averaged within $0.25 \times 0.25$ degrees gridboxes.

minimum error is reached around $2-3 \mathrm{~mm} / \mathrm{hr}$ when it is below $5 \%$. In the frame of this study, the BRAIN algorithm is applied for a number of rainy events over the Central and Eastern Mediterranean that occurred within the period September 2003-April 2004. The algorithm results (precipitation rate) are compared against PR 2A25 data but also they are also correlated with the lightning activity over the area.

\section{Methodology - Results}

\subsection{BRAIN vs. PR data}

BRAIN precipitation retrievals are produced by the algorithm as orbital data since they are derived from the colocation of orbital PR and TMI data, including two categories of rain rate - total and convective. Then, they are converted to gridded files with $0.25 \times 0.25$ degrees resolution for the area of our study (10-35 E, 30-40 N). Each grid box is characterised by the average of total and convective rain values that lie inside this box. The same conversion is applied to the PR near surface rainfall rate orbital data. The comparison was made for 31 overpasses of TRMM satellite with an adequate coverage of the area of interest by the PR instrument during the 6-month period October 2003-March 2004. Note that the PR swath is quite narrow $(247 \mathrm{~km}$ width since August 2001), with a northern limit of coverage at about $36 \mathrm{~N}$ and this makes it very difficult to have a large number of orbits covering adequately the study area.

In general, as the scatter plot shows (Fig. 1), the BRAIN algorithm provides lower values of rain rate than those measured by PR. Viltard et al. (2006) have pointed out that the BRAIN algorithm tends to underestimate the heavy near- surface rain rates. Moreover, it should be taken into consideration that the PR 2 A25 product sometime shows an unexpectedly high surface rain rates when checked against the TMI brightness temperature signatures and this can be attributed to possible contamination of the signal by ground echoes. However, both methods seem to identify the same rain areas regardless the value of rainfall rate, as indicated by a rather good correlation between the PR data and the BRAIN algorithm results (correlation coefficient equal to 0.75 ).

It would be instructive here to look at some individual cases and compare the rain rates estimates by PR data and from the BRAIN algorithm. Figure 2 presents results of the application of BRAIN algorithm over Sidra Gulf (offshore Tunisia) as well as PR-derived precipitation rates, at $\sim 03: 00$ UTC 18 October 2003, while Fig. 3 presents the corresponding fields over the area of Crete island at $\sim$ 15:00 UTC 05 November 2003. For comparison, lightning flashes maps as recorded by the ATD (Arrival Time Difference) system operated by the UK Metoffice within a time window of \pm 10 around the TRMM overpass are also presented. The visual inspection of the first case (Fig. 2) shows that the areal coverage of rainfall is very similar in both datasets, while in an area in the southeastern part of the domain there is a noticeable difference between high values of rain rate in PR estimates (Fig. 2b) and BRAIN results (Fig. 2a). Comparison with the corresponding lightning activity (Fig. 2c) shows that this area is void of lightning flashes indication that no convective activity is evident in the area, an activity that is suggested by the high values of PR rainrates but not evident in the BRAIN retrievals. However, the difference between PR and BRAIN precipitation rates over this area can be also attributed to resolution differences. Indeed, the localized high values of PR rainrates (few pixels shown in Fig. 2b) are probably filtered out in the coarser resolution of BRAIN retrievals $(12.5 \mathrm{~km})$. Significant discrepancies are also shown in Fig. 3, especially over western Crete. High precipitation rates over this area depicted in PR data (Fig. 3b) are not evident in the BRAIN retrievals (Fig. 3a), while over the sea the precipitation pattern shows a greater resemblance between the two datasets. Again, comparison with the lightning activity (Fig. 3c) suggests that the significant activity provided by PR over western Crete could be an artifact, possibly due to ground echo contamination of the signal backscattered to PR. However, there is a possibility that the rain seen by PR over western Crete is associated with non-convective precipitation that cannot be retrieved by BRAIN over land.

\subsection{BRAIN vs. ATD data}

In this section, BRAIN precipitation rates are compared against lightning data (cloud-to-ground flashes), also provided by the ATD system. For the comparison, BRAIN orbital data are again converted to gridded files with $0.25 \times 0.25$ degrees resolution for the area of our study (10-35 E, 30$40 \mathrm{~N}$ ), but in this case each grid box is characterised by the maxima of total and convective rain values that lie inside it. 

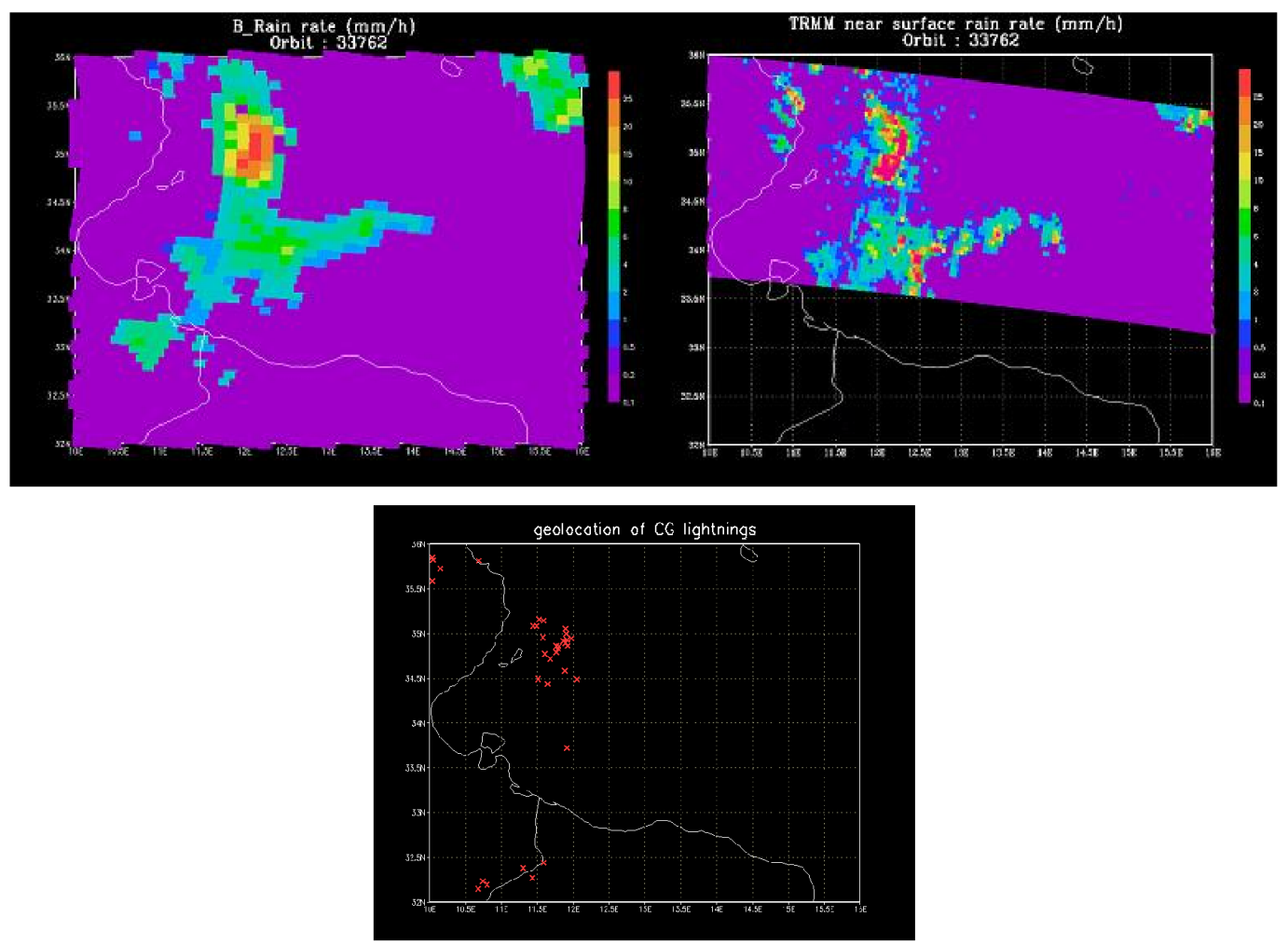

Fig. 2. (a) BRAIN rain rate (in $\mathrm{mm} / \mathrm{h}$ ) at 03:00 UTC 18 October 2003. (b) As in Fig. 2a, except for the PR rain rate. (c) Location of lightning flashes recorder by the ATD system within a time window of 10 min around the TRMM overpass.
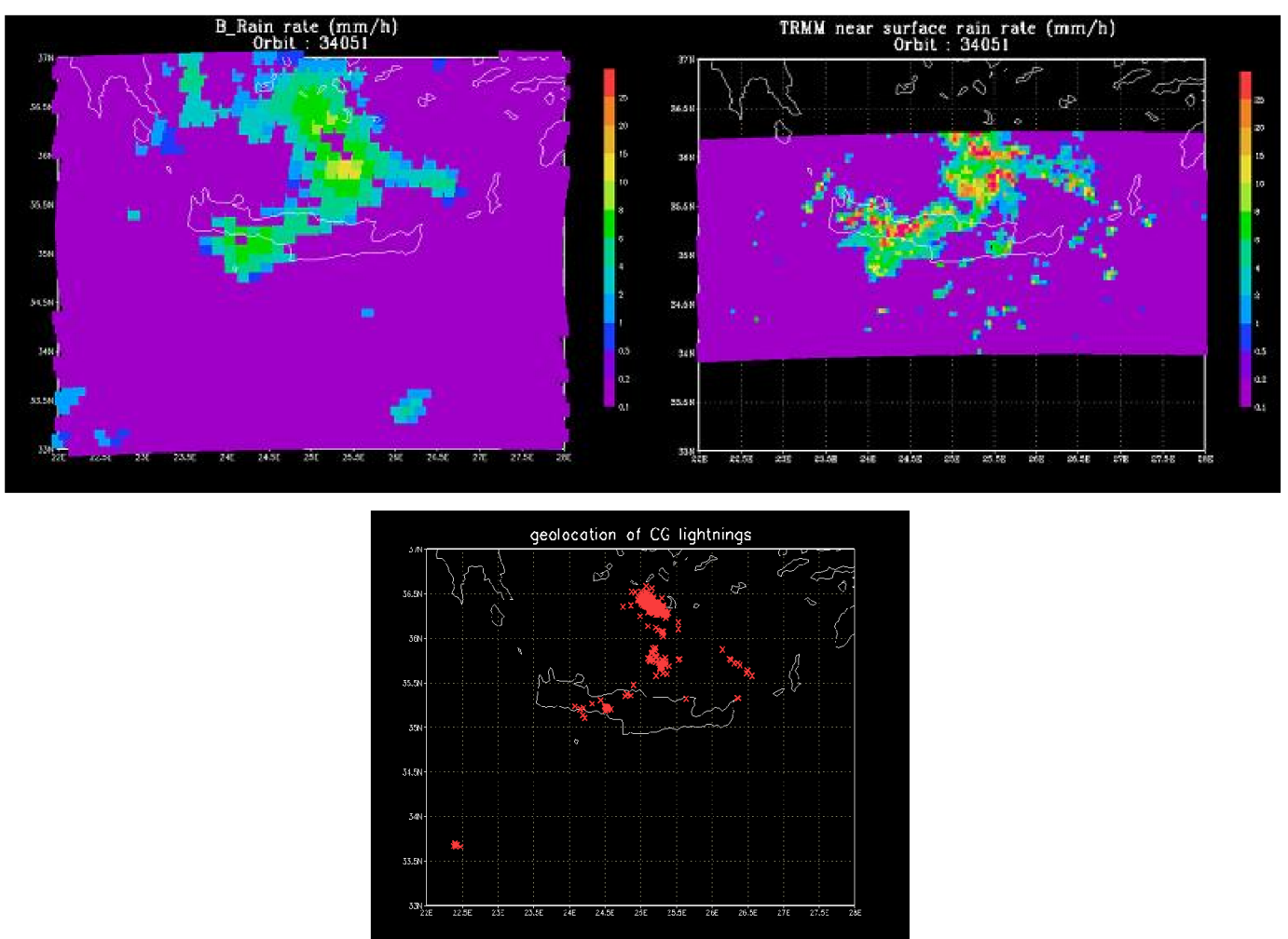

Fig. 3. (a) BRAIN rain rate (in $\mathrm{mm} / \mathrm{h}$ ) at 15:00 UTC 05 November 2003. (b) As in Fig. 3a, except for the PR rain rate. (c) Location of lightning flashes recorder by the ATD system within a time window of $10 \mathrm{~min}$ around the TRMM overpass. 


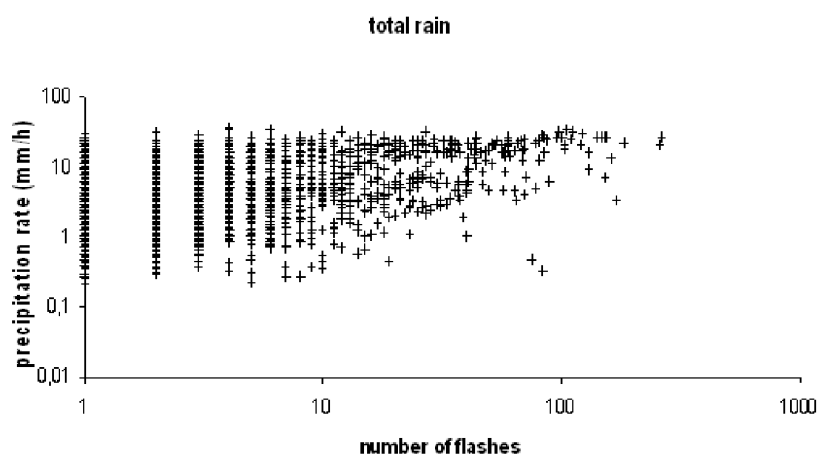

Fig. 4. Distribution of total rain rate versus the number of recorded flashes.

A similar gridded conversion is applied to the ATD data and each $0.25 \times 0.25$ deg grid box is characterised by the number of recorded flashes that lie inside the grid box within a time window of $\pm 10 \mathrm{~min}$ from TRMM overpass time.

The comparison between BRAIN precipitation estimates and flash density is made for 120 TRMM overpasses during the same 6-month period (October 2003-March 2004). The number of overpasses is larger than that of Sect. 2a, since TMI instrument has a wider swath $(878 \mathrm{~km}$ since August 2001) than PR and therefore it is easier to have adequate coverage of the study area.

Figure 4 presents a scatter plot of the distribution of BRAIN total rain rate versus the density of recorded flashes. This plot shows that as the number of flashes within a gridbox increases, the corresponding precipitation rate shows a similar positive trend and that when exceeding a significant number of flashes (i.e. 10) the majority of corresponding grid boxes have precipitation rates that exceed a few $\mathrm{mm} / \mathrm{h}$.

In order to get a better insight of the correlation between lightning flashes and BRAIN precipitation rates, the frequency distribution of precipitation rate for the cases with and without recorded lightning activity is discussed. Figure 5a shows the relative frequency (as a percentage) of various thresholds of precipitation rate (in logarithmic scale) for the grid boxes with recorded flashes with the cumulative frequency in the same graph. It is evident from the relative frequency distribution that there is a clear maximum at 0.7 (that corresponds to precipitation rate of $5 \mathrm{~mm} / \mathrm{h}$ ), while the whole distribution is skewed towards high values of precipitation rates. Moreover, from the cumulative frequency it is evident that in almost $90 \%$ of grid boxes with recorded lightning the precipitation rate is greater than $1 \mathrm{~mm} / \mathrm{h}(0$ in the $\log$ scale), while in $40 \%$ of them the precipitation rate is greater than $5 \mathrm{~mm} / \mathrm{h}(0.7$ in the $\log$ scale $)$ and in $20 \%$ greater than $10 \mathrm{~mm} / \mathrm{h}$ ( 1 in the log scale).

Finally, Fig. 5b shows the relative frequency (as percentage) of various thresholds of total precipitation rate (in logarithmic scale) as well as the cumulative percentage for the grid boxes without recorded lightnings. The relatively frequency distribution is now skewed towards the lower precipitation rates and the maximum is evident at -0.9 that cor-

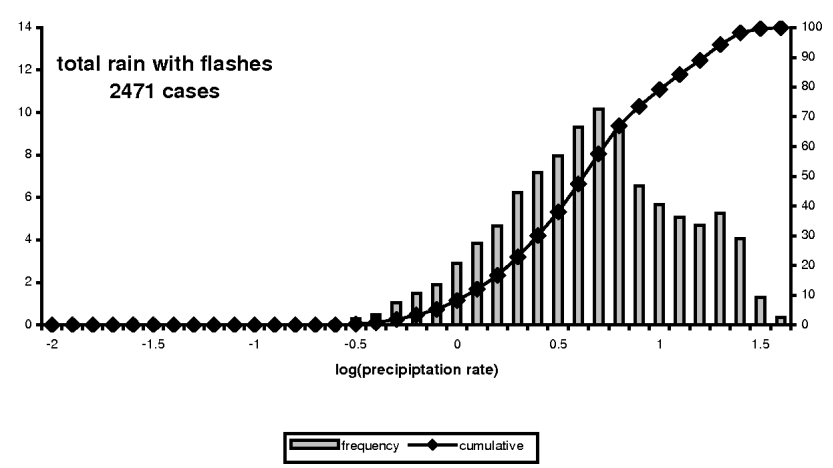

Fig. 5a. Frequency distribution of total rain rate (in logarithmic scale) for the cases with recorded flashes.

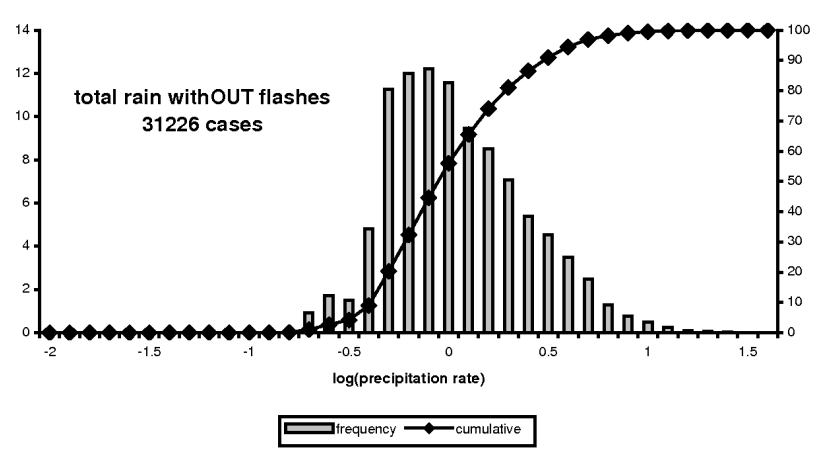

Fig. 5b. Frequency distribution of total rain rate (in logarithmic scale) for the cases without recorded flashes.

responds to precipitation rate of $0.8 \mathrm{~mm} / \mathrm{h}$. From the cumulative frequency it is evident that for only $45 \%$ of the grid boxes without lightning the precipitation rate is greater than $1 \mathrm{~mm} / \mathrm{h}, 5 \%$ greater than $5 \mathrm{~mm} / \mathrm{h}$ and less than $1 \%$ greater than $10 \mathrm{~mm} / \mathrm{h}$.

\section{Concluding remarks}

This study is devoted to the discussion of the first results of the application of the BRAIN algorithm for rainfall retrieval from satellite data, performed over Central and Eastern Mediterranean Sea during winter. The algorithm retrievals were compared with the estimates provided by the spaceborne radar (PR/TRMM). The comparison showed that the algorithm tends to underestimate some of the very high rain rates (mostly isolated pixels) evident in the PR rain estimates, a fact that can be attributed to the coarser resolution of BRAIN retrievals $(\sim 12.5 \mathrm{~km})$ with respect to PR resolution $(\sim 4 \mathrm{~km})$. This difference can also be ascribed to possible signal contamination by ground echoes that affect the PR measurements but also to the tendency of the BRAIN algorithm to underestimate very high rain raites (Viltard et al., 2006). Inspection of two individual cases showed indeed a better correlation of BRAIN rain estimates with the lightning 
activity in the area, but again a definitive conclusion cannot be drawn on the absence of ground-truth information.

Concerning the correlation between lightning activity and BRAIN retrievals, there is a clear difference of frequency distribution of precipitation rates with and without lightning activity, with a clear shift of the distribution towards higher precipitation rates in presence of lightning activity.

The aforementioned results show that BRAIN algorithm can be a useful tool for the retrieval of rain over the Mediterranean region. It is in the author's plans to continue the evaluation of the algorithm and the comparison against PR data for a larger number of cases over the area, including the winter period of 2005-2006 during which a network of raingauges was deployed over Crete.

Acknowledgements. This work has been jointly financed by the European Union (75\%) and the Greek Ministry of Development $(25 \%)$ in the framework of the program "Competitiveness - Promotion of Excellence in Technological Development and Research - Excellence in Research Centers, Action 3.3.1", (MIS64563). The authors are also grateful to UK Meteorological Office for providing the ATD data and to NASA Goddard Distributed Active Archive Center (DAAC) for providing TRMM data (TMI and PR).

Edited by: V. Kotroni and K. Lagouvardos Reviewed by: anonymous referee

\section{References}

Bauer, P.: Over-ocean rainfall retrieval from multisensor data of the tropical rainfall measuring mission. Part I: Design and Evaluation of Inversion Databases, J. Atm. Oceanic Technol., 18, 13151330, 2001.

Bauer, P., Amayenc, P., Kummerow, C. D., and Smith, E. A.: Overocean rainfall retrieval from multisensor data of the tropical rainfall measuring mission. Part II: Algorithm implementation, J. Atm. Oceanic Technol., 18, 1838-1855, 2001.

Kummerow, C., Olson, W. S., and Giglio, L.: A simplified scheme for obtaining precipitation and vertical hydrometeor profiles from passive microwave sensors, IEEE Trans. Geosci. Rem. Sens, 34, 1213-1232, 1996.

Kummerow, C., Hong, Y., Olson, W. S., Adler, R. F., McCollum, J., Ferraro, R., Petty, G., Shin, B.-B., and Wilheit, T. T.: The evolution of the Goddard profiling algorithm (GPROF) for rainfall estimation from passive microwave sensors, J. Appl. Meteor., 39, 1801-1820, 2001.

Moreau, E., Mallet, C., Thiria, S., Mabboux, B., Badran, F., and Klapisz, C.: Atmospheric liquid water retrieval using gated expert neural network, J. Atmos. Oceanic Technol., 19, 457-467, 2002.

Olson, W. S., Kummerow, C. D., Heymsfield, G. M., and Giglio, L.: A method for combined passive-active microwave retrievals of clouds and precipitation profiles, J. Appl. Meteor., 35, 17631789, 1996.

Panegrossi, G., Dietrich, S., Marzano, F. S., Mugnai, A., Smith, E. A., Xiang, X., Tripoli, G. J., Wang, P. K., and Poiares Baptista, J. P. V.: Use of Cloud Model Microphysics for Passive MicrowaveBased Precipitation Retrieval: Significance of Consistency between Model and Measurement Manifolds, J. Atmos. Sci., 55, 1644-1673, 1998.

Viltard, N., Kummerow, C., Olson, W. S., and Hong, Y.: Combined use of the radar and radiometer of TRMM to estimate the influence of drop size distribution on rain retrievals, J. Appl. Meteor., 39, 2103-2114, 2000.

Viltard, N., Burlaud, C., and Kummerow, C.: Rain Retrieval from TMI Brightness Temperature Measurements Using a TRMM PRBased Database, J. Appl. Meteor., 45, 455-466, 2006. 